\title{
INTERCEPTAÇÃO DA CHUVA POR DUAS ESPÉCIES ARBÓREAS EM ÁREAS VERDES URBANAS
}

\author{
Luzia Ferreira da Silva ${ }^{1}$, Ana Maria Liner Pereira Lima², \\ Demóstenes Ferreira da Silva Filho ${ }^{3}$, Hilton Thadeu Zarate do Couto ${ }^{4}$
}

(recebido: 24 de abril de 2009; aceito: 30 de agosto de 2010)

\begin{abstract}
RESUMO: O processo de interceptação da água da chuva foi analisado em duas espécies de maior frequência na arborização urbana, visando a obter a quantidade de interceptação (I) ou perda por interceptação, precipitação interna (PI), escoamento pelo tronco (Et) e precipitação total (PT). As espécies escolhidas foram Caesalpinia pluviosa DC. (Fabaceae: Caesalpinoideae) ou sibipiruna e Tipuana tipu O. Kuntze (Fabaceae: Faboideae) ou tipuana, com mais de 50 anos de idade, sendo três indivíduos isolados e três em grupo de cada espécie, plantadas no campus da ESALQ/USP onde o experimento foi realizado, durante o período de janeiro a fevereiro de 2007. As medições foram coletadas por meio de baldes de sete litros de capacidade de água, tanto na extremidade como no centro da copa. A PI apresentou alta correlação com a quantidade de PT, no centro da copa, em tipuana e na extremidade, em sibipiruna. O Et e a I tiveram baixa correlação com a quantidade de PT, nas duas espécies. As porcentagens médias de interceptação foram maiores na extremidade da copa nos indivíduos de sibipiruna, com 60,6\%, e no centro da tipuana, com 59,40\%. Desse modo, as duas espécies interceptaram até $60 \%$ das águas da chuva, o que propiciou grande potencial para serem plantadas no ambiente urbano.
\end{abstract}

Palavras-chave: Precipitação interna, escoamento pelo tronco, árvores urbanas.

\section{RAINFALL INTERCEPTION BY TWO ARBOREAL SPECIES IN URBAN GREEN AREA}

\begin{abstract}
Rainfall interception by the two most usual species in forest urban spaces was analysed by measuring of interception (I) or interception losses, through fall (PI), stem flow (Et) and gross precipitation (PT). The chosen species were Caesalpinia pluviosa DC. (Fabaceae: Caesalpinoideae) or sibipiruna, and Tipuana tipu O. Kuntze (Fabaceae: Faboideae) or tipuana. The individuals analysed were more than 50 years old, with three separate individuals and three individuals in each studied group of species at the campus of "Luiz de Queiroz" College of Agriculture (University of São Paulo), Piracicaba. The experiments were carried out from January to February 2007. Water was collected using seven-litre pails, in the edges and in the centre of the canopies. A high correlation of Th with Pg was observed on the centre of the crow of tipuana and by the edges of sibipiruna. St and I had low correlation with Pg for both species. The average of rain interception was greater in the edges of the crow of sibipiruna individuals, $60.6 \%$, and in the centre of tipuana crow, $59.40 \%$. Thus, both species intercepted up to $60 \%$ of the water rainfall, which indicates a great potential of both species for arborisation in urban environments.
\end{abstract}

Key words: Stem flow, through fall, urban tree.

\section{INTRODUÇÃO}

O ambiente urbano sofre grandes variações ambientais e dentre as mais comuns, estão as ilhas de calor, a poluição atmosférica e as inundações nas áreas urbanas. Essas variações ocorrem em razão das altas taxas de urbanização que se registram nos dias atuais, aumentando a impermeabilização do solo, a quantidade de veículos e indústrias e a canalização de rios que as atravessam.
Em consequência, nota-se um problema comum, que vem se agravando nos últimos tempos, em várias cidades, que é a enchente. Esse fato traz grande preocupação, tanto para os cientistas como à população, pois envolve a área urbana, onde habita o maior contingente de pessoas.

Embora haja essa preocupação com o clima, as pessoas não observam o benefício que as árvores podem oferecer, pois, além da sombra, interceptam e armazenam

${ }^{1}$ Engenheira Agrônoma, Professora Doutora em Fitotecnia - Unidade Acadêmica de Serra Talhada/UFRPE - Fazenda do Saco, s/n - Cx. P. 63 - 56900-000 - Serra Talhada, PE - luzia@uast.ufrpe.br

${ }^{2}$ Engenheira Agrônoma, Professora Doutora em Fitotecnia - Departamento de Produção Vegetal/DPV - Escola Superior de Agricultura Luiz de Queiroz/ESALQ - Universidade de São Paulo/USP - Cx P. 9 - Rua Pádua dias, 11 - 13418-900 - Piracicaba, SP amlplima@esalq.usp.br

${ }^{3}$ Engenheiro Agrônomo, Professor Doutor em Silvicultura Urbana - Departamento de Ciências Florestais - Escola Superior de Agricultura Luiz de Queiroz/ESALQ - Universidade de São Paulo/USP - Cx P. 9 - Rua Pádua dias, 11 - 13418-900 - Piracicaba, SP dfsilva@esalq.usp.br

${ }^{4}$ Engenheiro Agrônomo, Professor Doutor em Bioestatística e Inventário Florestal - Departamento de Ciências Florestais - Escola Superior de Agricultura Luiz de Queiroz/ESALQ - Universidade de São Paulo/USP - Cx P. 9 - Rua Pádua dias, 11 - 13418-900 Piracicaba, SP - htzcouto@esalq.usp.br

Cerne, Lavras, v. 16, n. 4, p. 547-555, out./dez. 2010 
parte da água da chuva por meio das folhas e da superfície dos ramos; em consequência, reduzem o volume do escoamento superficial e retardam a formação de correntezas (XIAO et al., 1998).

A interceptação pelas copas das árvores é um componente importante no ciclo hidrológico urbano, pois influencia na redistribuição da água da chuva, no amortecimento, no direcionamento e na retenção das gotas que chegam ao solo, afetando a dinâmica do escoamento superficial e o processo de infiltração (OLIVEIRA JÚNIOR \& DIAS, 2005).

A interceptação da chuva pela cobertura florestal representa uma importante parcela de chuva que cai e retorna à atmosfera por evaporação, antes de chegar ao solo, contribuindo com a massa de vapor de água precipitável na atmosfera (FERREIRA et al., 2005). Quando a cobertura florestal é ausente, ocorrem variações no escoamento superficial e na intensidade de chuva em determinados locais, como analisado no trabalho de Li et al. (2007), que mediram a sensibilidade hidrológica no solo do Oeste da África e observaram que em florestas tropicais o desmatamento total da área aumenta a taxa de escoamento superficial de $0,15 \%$ para $0,44 \%$ e, quanto maior o desmatamento, maior será a intensidade de chuva medida em milímetros.

Nas florestas, o estudo de interceptação tem o objetivo de elaborar normas de manejo das espécies, enquanto que, para as árvores urbanas isoladas verificar a proteção da qualidade da água e o controle de poluentes e enchentes (XIAO \& McPHERSON, 2003).

No trabalho de xiao \& mcpherson (2009), foi verificado que no local onde foram aplicadas as boas práticas de manejo, com plantio de árvores e cobertura morta, o escoamento superficial da chuva foi significativamente reduzido em $94 \%$. A quantidade de poluentes também foi reduzida $(95,4 \%)$ e o crescimento das árvores foi favorecido em razão da alta porosidade o solo, que proporciona maior armazenamento de água e boa aeração para o sistema radicular.

Na arborização urbana, não há estudos suficientes sobre a interceptação da água da chuva pelas copas das árvores que abranjam nossas condições tropicais, principalmente em relação às enchentes. Ainda, existe um elevado índice de supressão ou substituição das árvores viárias por arbustos, deixando as cidades com poucas áreas verdes e sem sombreamento.

A Caesalpinia pluviosa DC. (Fabaceae: Caesalpinoideae) ou sibipiruna e a Tipuana tipu (Benth.)
O. Kuntze (Fabaceae: Faboideae) ou tipuana tiveram grande destaque na arborização urbana em décadas passadas, segundo inventário feito em Piracicaba/SP por Lima et al. (1994); porém, atualmente, constata-se a perda do interesse da população pelas referidas espécies e as substituem por arbustos, para evitar maiores riscos.

Nesse propósito, realizou-se um experimento no campus da ESALQ/USP, com essas duas espécies, para avaliar a capacidade de interceptação da água da chuva pelas copas, o que poderá minimizar enchentes em áreas urbanas.

\section{MATERIAL E MÉTODOS}

\subsection{Local de estudo}

O município de Piracicaba se encontra entre as coordenadas geográficas de $22^{\circ} 42^{\prime} 30^{\prime \prime}$ de latitude sul e $47^{\circ} 38^{\prime} 00^{\prime \prime}$ de longitude a oeste, com altitude média S.N.M. de $546 \mathrm{~m}$. O clima é do tipo Cwa: mesotérmico de inverno seco. A precipitação média anual é, aproximadamente, 1.280 $\mathrm{mm}$, sendo que, cerca de $1.000 \mathrm{~mm}$ ou $78 \%$ desse total, caem durante a estação chuvosa (verão), que vai de outubro a março (Estação Meteorológica da ESALQ/USP). A temperatura média anual é de $20^{\circ} \mathrm{C}$.

$\mathrm{O}$ período experimental ocorreu nos meses de janeiro a fevereiro de 2007. Cruciani et al. (2002) constataram que o mês de março é o mais crítico em relação à intensidade de chuvas, pois choveu muito durante o período de 60 minutos, entre 1966 a 2000. No entanto, a partir de 2001, a precipitação no mês de janeiro vem apresentando maior índice pluviométrico, fato que justifica as coletas deste trabalho terem sido feitas durante o período de janeiro a fevereiro.

As sibipirunas e as tipuanas foram plantadas na década de 50, no campus da Escola Superior de Agricultura "Luiz de Queiroz", em Piracicaba/SP.

\subsection{Espécies estudadas}

A sibipiruna é uma espécie ornamental e com potencial madeireiro. Ela é encontrada, principalmente, na região de Mata Atlântica do Rio de Janeiro; é semidecídua e heliófita, produzindo, anualmente, grande quantidade de sementes. Suas flores são zigomorficas, racemosas terminais, amarelas, dispostas em cachos cônicos e eretos, com ocorrência na primavera. A folhagem cai parcialmente nos meses de inverno e é composta bi-pinadas, sem glândulas no ráquis e de pequenos folíolos. Os frutos são deiscentes de cor bege-claro, tipo legume achatado e as sementes têm cerca de $3 \mathrm{~cm}$ de diâmetro. Seu porte pode

Cerne, Lavras, v. 16, n. 4, p. 547-555, out./dez. 2010 
chegar até 20 metros de altura, com copa arredondada de aproximadamente 15 metros de diâmetro e seus ramos são ortotrópicos, que crescem verticalmente (ENDRESS, 1994; HALLÉ et al., 1978; LORENZI, 1992; VIDAL \& VIDAL, 1992).

A tipuana é nativa da Argentina e da Bolívia, sendo mais comum no sul do Brasil. Tem florescimento na primavera, com cachos de flores amarelo-ouro, de simetria zigomorfa e aroma agradável. Seus frutos são indeiscentes, tipo sâmara, com pericarpo seco e alado, monospérmicos e mais frequentes no outono; o tronco é rústico, de casca escura e superfície enrugada. As folhas são compostas pinadas de folíolos ovais que caem no inverno e com pulvinos e estípulas. $\mathrm{O}$ porte pode atingir até 25 metros de altura, com copa larga de até 20 metros de diâmetro e seus ramos plagiotrópicos são quase horizontais (HALLÉ et al., 1978; MARTINS \& OLIVEIRA, 2001; VIDAL \& VIDAL, 1992).

As espécies apresentaram divergências nos modelos de ramificação (ortotrópicos e plagiotrópicos), na estrutura da folha (folíolos pequenos e formato oval), nas flores (terminais e não terminais), nos frutos (deiscentelegume e indeiscente-sâmara) e no caule (superfície menos enrugada e muito enrugada).

Para cada espécie estudada, considerou-se seis indivíduos, sendo três isolados de sibipiruna, com a identificação de S1, S5 e S6 e três em grupo ou com as copas próximas, indicados por $\mathrm{S} 234$ e três isolados de tipuanas, com a identificação T1, T5 e T6 e três em grupo ou com as copas próximas, definidas como T234. Eles estavam distribuídos em uma área de 1 hectare, aproximadamente, distanciados de 6 a $100 \mathrm{~m}$ e foram avaliados o diâmetro à altura do peito (DAP), a altura, o diâmetro e a área da copa.

Os valores do diâmetro e área da copa foram registrados por meio de imagem aérea de videografia, obtida em agosto de 2005 e também com trena pelo método quadrante. $\mathrm{O}$ aparelho hipsômetro foi usado para medir a altura das árvores. As medidas do DAP e da altura dos indivíduos, em grupo, foram feitas pela média aritmética dos três indivíduos.

\subsection{Medidas de interceptação}

A precipitação foi coletada por meio de 180 baldes de 7 litros de capacidade de água, com diâmetro de $23 \mathrm{~cm}$ e altura de $22 \mathrm{~cm}$, e medida imediatamente após cada evento, por provetas graduadas de $100 \mathrm{ml} \mathrm{e} 1.000 \mathrm{ml}$.

$\mathrm{O}$ escoamento pelo tronco foi coletado por meio de canaletas feitas por espuma de poliuretano, colocadas em cada tronco até o término do experimento. Essa espuma é líquida e quando é agitada e aplicada no tronco, expande e alguns minutos depois fica rígida (LIKENS \& EATON, 1970). Antes de enrijecer, foi manuseada até adquirir formato de canaletas, onde escoaram as águas para os baldes.

Os baldes foram distribuídos aleatoriamente, tanto no centro como na extremidade da copa e amparados por estacas de ferro de $30 \mathrm{~cm}$, para mantê-los fixos ao longo do período experimental. A medição da proveta graduada foi registrada em planilhas, após meia ou uma hora a cada evento de chuva. Posteriormente, os valores volumétricos coletados foram tabulados em milímetros de altura de água.

A precipitação total (PT), que é medida em terreno aberto, foi coletada por cinco baldes distribuídos em área próxima de cada indivíduo ou no grupo, com, aproximadamente, 5 a $20 \mathrm{~m}$ de distância entre eles. A precipitação interna (PI), que é a chuva que atinge o solo, tanto pelas gotas que passam diretamente pelas aberturas existentes entre as copas, como as que respingam dessas, também foi medida por baldes abaixo de cada copa, sendo que, cinco baldes foram colocados em sua extremidade e os outros cinco no centro. $\mathrm{O}$ escoamento pelo tronco das árvores (Et), igualmente, foi medido por baldes que foram colocados sob as canaletas formadas pela espuma de poliuretano (Figura 1).

A medição do escoamento pelo tronco, nos indivíduos isolados, foi feita com baldes em quantidades proporcionais a capacidade de escoamento de água e tamanho do diâmetro à altura do peito (DAP). Nas espécies em grupo, foi usada a média aritmética dos três troncos para conversão do volume coletado em milímetro de altura de água.

O volume de água coletada em cada indivíduo isolado e do grupo foi medido pela média aritmética dos cinco baldes colocados em terreno aberto (PT), na extremidade e no centro (PI) das copas.

A interceptação ou perda por interceptação (I) é a água interceptada pelas copas que não atinge o solo; pode ser calculada pela diferença entre a precipitação total (PT) e a precipitação interna (PI), sem levar em conta o aspecto físico, que é a evaporação para a atmosfera.

\subsection{Análise dos dados}

Os dados de precipitação total, interna, escoamento pelo tronco foram analisados estatisticamente, utilizando a análise de variância e a comparação das médias pelo teste Tukey, ao nível de 5\% de probabilidade, e submetidos ao programa Statistical Analysis System (SAS 9.1). O delineamento experimental utilizado foi inteiramente 

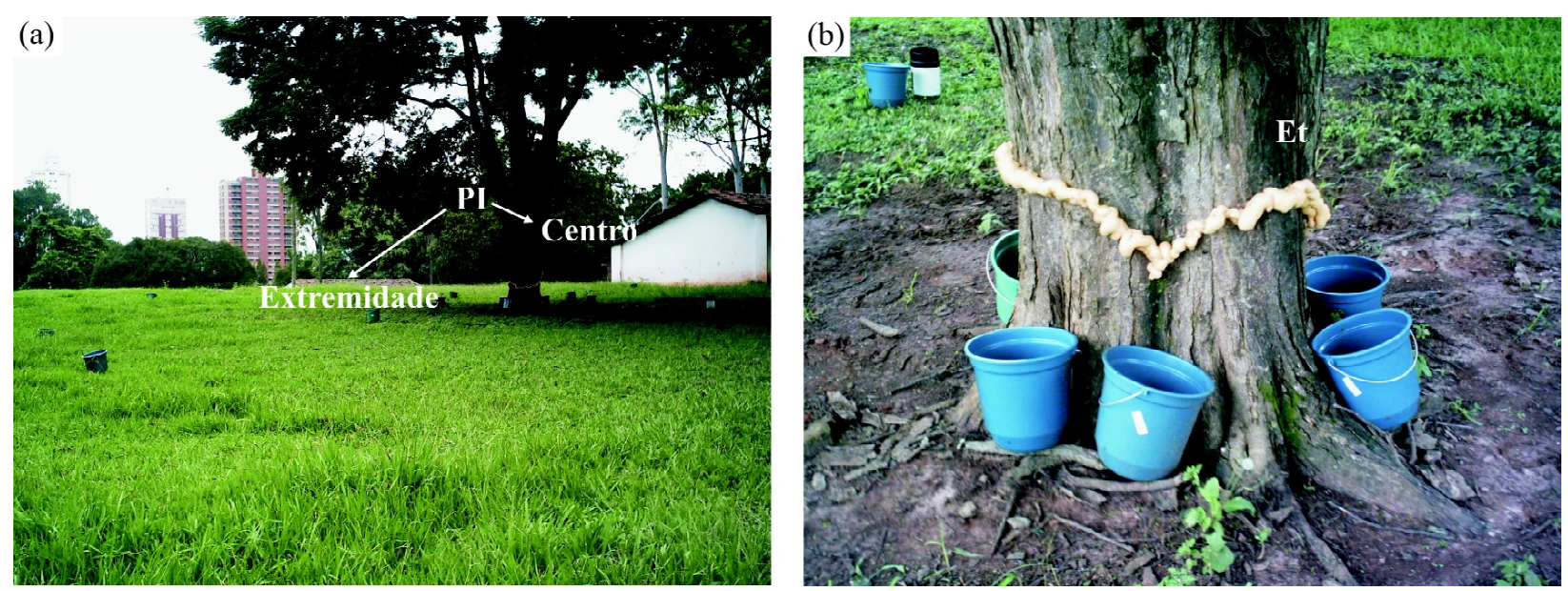

Figura 1 - (a) Distribuição dos baldes no terreno aberto, na extremidade e centro da copa; (b) Escoamento pelo tronco, conduzidos por espuma de poliuretano na espécie de Caesalpina pluviosa DC. (sibipiruna).

Figure 1 - (a) Distribution of pails in open terrain by the edges and in the centre of the canopy; (b) Stem flow led by polyurethane foam in sibipiruna (Caesalpinia pluviosa DC.) trunk.

causalizado, em esquema fatorial com os seguintes níveis: indivíduos de duas espécies isolados ou em grupo (8), condições a que foram submetidas (3), e os eventos que sucederam durante o experimento (31). A subdivisão de cada nível foi sistematizada da seguinte forma: os indivíduos das espécies foram distribuídos em tipuana 1 (T1), tipuana grupo (T234), tipuana 5 (T5), tipuana 6 (T6), sibipiruna 1 (S1), sibipiruna grupo (S234), sibipiruna 5 (S5) e sibipiruna 6 (S6); as condições, em precipitação total (PT), precipitação interna (PI) e escoamento pelo tronco (Et) e os eventos de chuvas que ocorreram nos meses de janeiro a fevereiro de 2007 (E1 até E31).

\section{RESULTADOS E DISCUSSÃO}

Durante os meses de janeiro e fevereiro de 2007, choveram 34 dias, com média mensal de $259,0 \mathrm{~mm}$ e 228,3 $\mathrm{mm}$, respectivamente, enquanto que, em 2006, houve dois dias a mais de chuva (36 dias), porém em menor intensidade, com 225,2 mm em janeiro e 164,8 mm em fevereiro, segundo a Estação Meteorológica da ESALQ/USP.

No período experimental, foram medidos 31 eventos em 21 dias, com variações de chuvas entre o mínimo de 0,21 mm até o máximo de 30,82 $\mathrm{mm}$. A maioria das coletas realizadas foi em único evento por dia, mas sete delas ocorreram em dois ou três eventos diários, com intervalo de meia a uma hora entre eles.

O indivíduo de tipuana 1 (T1), na Tabela 1 , apresentou diferença significativa e foi o único que melhor respondeu as precipitações ocorridas nas copas, durante a época do experimento, enquanto que os demais indivíduos sofreram alta variabilidade, principalmente os de sibipiruna. O coeficiente de variação $(\mathrm{CV})$ demonstrou essa alta variabilidade, que pode estar relacionada com as diferenças de intensidade e duração de chuvas (Tabela 1).

Do mesmo modo, os indivíduos de sibipiruna também apresentaram alta variabilidade quanto à porcentagem média de interceptação da chuva, tanto na extremidade como no centro da copa (Figura 2) e, ainda, menor porcentagem de interceptação do que os indivíduos de tipuanas. Contudo, existe uma alta porcentagem de interceptação na extremidade da copa de sibipiruna (S1) $(60,06 \%)$ que pode estar relacionada com a baixa intervenção do vento, pois, quando esse não for tão evidente, pode aumentar a capacidade de armazenamento de água na copa, influenciando, positivamente, $\mathrm{o}$ fator interceptação.

No trabalho de Xiao et al. (2000), não foi considerada a velocidade do vento maior que $15 \mathrm{Km} / \mathrm{h}$, uma vez que essa velocidade não deixava gotas de água nas copas e não deveria ser considerada para análise da precipitação interna. Para os autores, o vento altera o ângulo de incidência da chuva, quebra o equilíbrio temporário de armazenagem da água nas copas e proporciona o gotejamento que reduz a disponibilidade de água para evaporação.

No experimento, embora $42 \%$ de eventos tivessem apresentado valores de velocidade do vento maiores do que $15 \mathrm{Km} / \mathrm{h}$, as medições não foram afetadas, porque não

Cerne, Lavras, v. 16, n. 4, p. 547-555, out./dez. 2010 
Tabela 1 - Espécies avaliadas e precipitação geral, de janeiro a fevereiro de 2007, no campus da Escola Superior de Agricultura "Luiz de Queiroz", em Piracicaba/SP.

Table 1 - Species evaluated and total intercepted precipitation in January and February 2007 at the campus of the Agriculture College "Luiz de Queiroz", Piracicaba, Brazil.

\begin{tabular}{lccccc}
\hline Tipuanas & $\begin{array}{c}\text { Precipitação geral } \\
(\mathrm{mm})\end{array}$ & Sibipirunas & $\begin{array}{c}\text { Precipitação geral } \\
(\mathrm{mm})\end{array}$ & \multicolumn{2}{c}{ Teste F } \\
\hline T1 & $4,29 \mathrm{a}$ & $\mathrm{S} 1$ & $4,12 \mathrm{c}$ & $\mathrm{F}$ & 623,42 \\
T234 & $3,72 \mathrm{a} \mathrm{b} \mathrm{c}$ & $\mathrm{S} 234$ & $4,18 \mathrm{a} \mathrm{b}$ & $\mathrm{p}>\mathrm{F}$ & 0,0001 \\
T5 & $4,12 \mathrm{~b} \mathrm{c}$ & $\mathrm{S} 5$ & $4,06 \mathrm{a} \mathrm{b} \mathrm{c}$ & $\mathrm{CV} \%$ & 58,47 \\
T6 & $4,11 \mathrm{a} \mathrm{b} \mathrm{c}$ & $\mathrm{S} 6$ & $4,36 \mathrm{~b} \mathrm{c}$ & Média Geral & 4,12 \\
\hline
\end{tabular}

Médias seguidas de mesma letra não diferem significativamente pelo teste Tukey a $5 \%$ de probabilidade.

Porcentagem média de interceptação

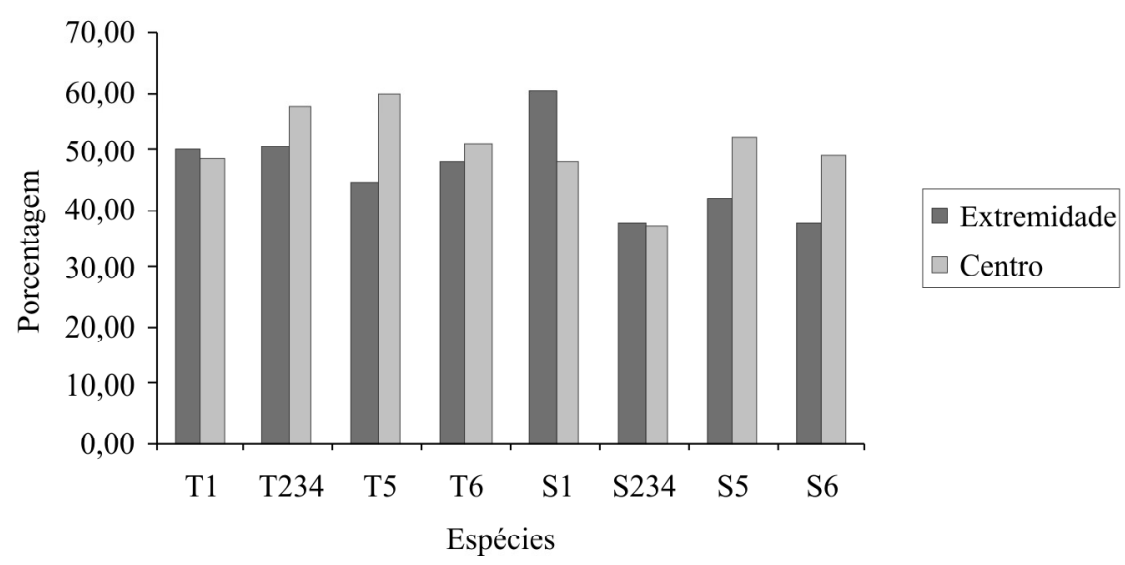

Figura 2 - Porcentagem média de interceptação nas duas espécies: tipuanas isoladas (T1, T5 e T6) e grupo (T234) e sibipirunas isoladas (S1, S5 e S6) e grupo (S234), durante o período de janeiro e fevereiro, no campus da ESALQ/USP.

Figure 2 - Mean percentages of interception of two species: isolated (T1, T5 and T6) and grouped (T234) tipuanas and isolated (S1, S5 and S6) and grouped (S234) sibipirunas during January and February, at the campus of the College of Agriculture "Luiz de Queiroz", Piracicaba.

houve correlação entre a velocidade do vento e a interceptação e o escoamento pelo tronco.

No entanto, a interceptação na extremidade da copa, em árvores isoladas, tem maior chance de sofrer interferências do meio, principalmente em relação à velocidade do vento, que contribui para menor precipitação interna em certos locais e, consequentemente, causa menor porcentagem de interceptação. Na maioria dos indivíduos analisados, a porcentagem média de interceptação foi maior no centro da copa do que na extremidade (Figura 2), tanto para as sibipirunas (S5 e S6) como para tipuanas, com exceção de tipuana 1 (T1).

No trabalho de Geiger (1961), foi observado que, em espécies de copas densas, com menor influência dos ventos, a interceptação na extremidade foi maior, por volta de $80 \%$ em relação à precipitação total.

Em florestas de eucalipto e pinheiro, Lima (1976) observou valores médios de perda por interceptação de $12,2 \%$ e $6,6 \%$, respectivamente, menores do que os encontrados nos indivíduos em grupo de tipuanas (T234) e sibipirunas (S234), com 57,74\% e 37,18\%, respectivamente, no centro da copa. Esse fato pode estar relacionado ao espaçamento entre árvores, pois as tipuanas apresentaram espaçamentos maiores, o que confere um bom desenvolvimento de copas, enquanto que o plantio de eucalipto e pinheiro têm espaçamento menor e sistematizado, de 3 por $2 \mathrm{~m}$ e suas copas têm limitações quanto ao desenvolvimento, em diâmetro.

Cerne, Lavras, v. 16, n. 4, p. 547-555, out./dez. 2010 
Em chuvas torrenciais, quando a copa estiver saturada, existe pouca influência de interceptação, portanto, a intensidade média de chuva é um campo a ser explorado mais profundamente, o que poderia entender as razões da interceptação, além de considerar a profundidade do lençol freático do local.

Para Xiao \& McPherson (2003), as árvores localizadas em parques (clareiras) e ruas (isoladas) possuem maior área de copas, o que proporciona maior capacidade de armazenamento de chuva.

Em todas as tipuanas, a precipitação total e o escoamento pelo tronco não tiveram diferença significativa, enquanto que, na precipitação interna, houve variação (Tabela 2). De acordo com Lima (1986), a precipitação interna (PI) apresenta alta variabilidade e requer a utilização de vários pluviômetros abaixo da copa para minimizar esse efeito. O uso de uma quantidade considerável de pluviômetros é recomendável para o cálculo da média nos espaços em que ocorre concentração de gotas de água, em certos pontos em detrimento de outros (REGALADO \& RITTER, 2010). Numa floresta, geralmente usa-se mais de 20 pluviômetros, que podem estar fixos ou recolocados casualmente na distribuição dos espaços para melhor quantificar o gotejamento da copa (HOLWERDA et al., 2006; LLOYD \& MARQUES, 1988).

Nesse experimento, foram colocados 10 baldes fixos sob cada copa ( 5 baldes na extremidade e 5 no centro), que substituíram os pluviômetros, para obter uma melhor estimativa dessa variação.

Outras possibilidades podem ser consideradas, como a velocidade do vento associada à chuva que muda a distribuição da precipitação interna e escoamento pelo tronco; o tamanho da árvore, com DAP alto; a grande diversidade de espécies com diferentes padrões fenológicos; as variações na superfície das folhas e caules; a alta variação espacial na cobertura da copa; a presença de epífitas; a área da superfície do caule e o ângulo de inclinação dos ramos (LEVIA JUNIOR \& FROST, 2003; McPHERSON, 1998; XIAO et al., 2000).

Segundo Lima (1986), a medição do escoamento pelo tronco é muito difícil e vários estudos têm mostrado que tal resultado constitui-se, apenas, em uma fração muito pequena da interceptação, que varia de espécie para espécie e deve ser medida em diversas árvores numa parcela florestal. Ainda, sofre intervenções em virtude da rugosidade da casca; em espécies de tronco liso o volume de escoamento é maior do que com casca rugosa. No trabalho, tal fato foi observado nos indivíduos de tipuana, cuja casca é rugosa, com média do volume do escoamento pelo tronco (Et) menor do que a sibipiruna. Nesse sentido, a sibipiruna apresentou uma variação maior de $50 \%$ a $90 \%$ do volume coletado nos indivíduos isolados, enquanto que, nos indivíduos em grupo, esse valor não foi alterado, como se pode conferir nas Tabelas 2 e 3 .

Assim como a tipuana, a sibipiruna apresentou variabilidade na precipitação interna (Tabela 3), como também, apresentou alta variabilidade nos resultados da precipitação total e de escoamento pelo tronco.

A análise por espécie confirma o que já foi observado na composição geral das espécies (Tabela 1) de que a sibipiruna sofreu maior variabilidade de precipitação e escoamento pelo tronco do que a tipuana.

Da mesma forma, os indivíduos de tipuana tiveram maiores porcentagens de interceptação, tanto na extremidade como no centro da copa, (Figura 2), fato que pode estar relacionado com a arquitetura da copa, pois seus ramos são plagiotrópicos, mais posicionados na horizontal, o que pode conferir maior porcentagem de interceptação.

Tabela 2 - Tipuanas isoladas e em grupo, nas condições de precipitação, durante o período de janeiro e fevereiro de 2007, no campus da Escola Superior de Agricultura "Luiz de Queiroz", em Piracicaba/SP.

Table 2 - Isolated and grouped tipuanas in conditions of precipitation during January and February 2007, at the campus of College of Agriculture "Luiz de Queiroz", in Piracicaba, Brazil.

\begin{tabular}{cllll}
\hline \multirow{2}{*}{ Condições } & \multicolumn{5}{c}{ Tipuanas isoladas e em grupo } \\
\cline { 2 - 5 } & T1 & T234 & T5 & T6 \\
\hline PT & $5,33 \mathrm{a}$ & $5,50 \mathrm{a}$ & $5,30 \mathrm{a}$ & $5,35 \mathrm{a}$ \\
PI & $4,19 \quad \mathrm{~b}$ & $3,94 \quad \mathrm{~b}$ & $3,93 \mathrm{~b}$ & $3,90 \mathrm{~b}$ \\
E t & $0,08 \mathrm{a}$ & $0,02 \mathrm{a}$ & $0,05 \mathrm{a}$ & $0,07 \mathrm{a}$ \\
\hline
\end{tabular}

Médias seguidas de mesma letra não diferem significativamente pelo teste Tukey a 5\% de probabilidade.

Cerne, Lavras, v. 16, n. 4, p. 547-555, out./dez. 2010 
Além disso, as médias do escoamento pelo tronco em sibipiruna (Tabela 3) foram maiores do que nas tipuanas (Tabela 2), o que confirma que a posição dos galhos interfere na interceptação e escoamento pelo tronco.

Návar (1993) mediu o escoamento pelo tronco em três espécies arbustivas mais cultivadas no México e verificou que a medida do escoamento pelo tronco, na espécie Diospyrus texana Scheele, foi maior do que em Acacia farnesiana (L.) Willd. e Prosopis laevigata (Willd.) M. Johnston.

Esse fato ocorreu em razão do ângulo de inclinação dos galhos de D. texana que eram maiores que $70^{\circ}$ e $80^{\circ}$, como pode ser verificado em galhos de sibipiruna, que são mais voltados à posição vertical do que em tipuana. Tal observação foi constatada também por Xiao et al. (2000), na espécie Pyrus calleryana Dcne, que também obteve maior escoamento pelo tronco e, consequentemente, menor interceptação, pois seus galhos são, predominantemente, verticais.

$\mathrm{Na}$ Tabela 4, nota-se que, apenas os indivíduos em grupo de sibipiruna (S234), obtiveram os menores valores de DAP, com 0,36 m, e, consequentemente, os valores mais baixos de média de porcentagem de interceptação. O indivíduo de sibipiruna (S6) teve menor porcentagem de interceptação na extremidade, menor diâmetro e área da copa, em virtude de seus galhos apresentarem-se quebrados pelo vento.

De acordo com Xiao \& McPherson (2003), árvores adultas, com classes de DAP maiores que $0,30 \mathrm{~m}$, tiveram maiores valores de interceptação, principalmente a Liquidambar styraciflua L., que apresentou $70 \%$ de interceptação, com desfolhamento no inverno e no período chuvoso.

Tabela 3 - Sibipirunas isoladas e em grupo, nas condições de precipitação, durante o período de janeiro e fevereiro de 2007, no campus da Escola Superior de Agricultura "Luiz de Queiroz", em Piracicaba/SP.

Table 3 - Isolated and grouped sibipirunas in conditions of precipitation during January and Febuary 2007, at the campus of the College of Agriculture "Luiz de Queiroz”, in Piracicaba, Brazil.

\begin{tabular}{ccccc}
\hline \multirow{2}{*}{ Condições } & \multicolumn{6}{c}{ Sibipirunas isoladas e em grupo } \\
\cline { 2 - 6 } & $\mathrm{S} 1$ & $\mathrm{~S} 234$ & $\mathrm{~S} 5$ & $\mathrm{~S} 6$ \\
\hline PT & $5,48 \mathrm{~b}$ & $5,69 \mathrm{a}$ & $5,14 \mathrm{~b}$ & $5,40 \mathrm{a}$ \\
PI & $3,76 \quad \mathrm{c}$ & $4,67 \mathrm{~b}$ & $3,91 \mathrm{~b}$ & $4,26 \mathrm{~b}$ \\
Et & $0,82 \mathrm{a}$ & $0,02 \mathrm{~b}$ & $0,24 \mathrm{a}$ & $0,14 \quad \mathrm{c}$ \\
\hline
\end{tabular}

Médias seguidas de mesma letra não diferem significativamente pelo teste Tukey a $5 \%$ de probabilidade.

Tabela 4 - Diâmetro à altura do peito (DAP), porcentagem média da interceptação da chuva na extremidade e centro da copa, altura e diâmetro e área da copa, durante o período de janeiro e fevereiro de 2007, no campus da Escola Superior de Agricultura "Luiz de Queiroz”, em Piracicaba/SP, das espécies isoladas e em grupo de tipuana e sibipiruna.

Table 4 - Diameter at breast height $(D B H)$, mean percentage of rainfall interception by the edges of the canopy extremity and its centre, height, diameter and crown area, during January and February 2007, at the campus of the College of Agriculture "Luiz de Queiroz", in Piracicaba, Brazil, for isolated and grouped specimens of tipuana and sibipiruna trees.

\begin{tabular}{|c|c|c|c|c|c|c|}
\hline \multirow{2}{*}{ Espécies } & \multirow{2}{*}{$\mathrm{DAP}(\mathrm{m})$} & \multicolumn{2}{|c|}{ \% Interceptação } & \multirow{2}{*}{ Altura (m) } & \multicolumn{2}{|c|}{ Copa $\left(m^{2}\right)$} \\
\hline & & Extremidade & Centro & & Diâmetro & Área \\
\hline S1 & 0,75 & 60,06 & 47,91 & 16 & 16,04 & 165,78 \\
\hline S234 & 0,36 & 37,65 & 37,18 & 12,36 & 20,98 & 249,5 \\
\hline S5 & 0,76 & 41,79 & 52,47 & 13,2 & 21,12 & 266,46 \\
\hline S6 & 0,81 & 37,51 & 49,04 & 10,25 & 12,83 & 87,64 \\
\hline $\mathrm{T} 1$ & 0,87 & 50,06 & 48,76 & 13 & 17,49 & 215,31 \\
\hline $\mathrm{T} 234$ & 0,64 & 50,48 & 57,74 & 17 & 35,4 & 764,2 \\
\hline $\mathrm{T} 5$ & 0,7 & 44,43 & 59,40 & 14,25 & 18,29 & 202,53 \\
\hline T6 & 1,12 & 48,23 & 51,28 & 13,25 & 21,84 & 326,75 \\
\hline
\end{tabular}

Cerne, Lavras, v. 16, n. 4, p. 547-555, out./dez. 2010 
Nas condições da cidade de Piracicaba/SP, os valores de interceptação foram bem significativos, aproximando-se dos valores obtidos por Xiao \& McPherson (2003).

Nesse caso, tanto para a precipitação total como para a precipitação interna, os indivíduos em grupo (S234 e
T234), das espécies sibipiruna e tipuana, foram os que mais responderam significativamente, enquanto que, para o escoamento pelo tronco, apenas o indivíduo sibipiruna (S1) (Tabela 5). Portanto, na análise espécies isoladas podem ocorrer certas interferências de outros fatores, mencionados anteriormente, sendo objeto de estudos futuros.

Tabela 5 - Tipuanas e sibipirunas, isoladas e em grupo, precipitação total (PT), precipitação interna (PI) e escoamento pelo tronco (Et), durante o período de janeiro e fevereiro de 2007, no campus da Escola Superior de Agricultura "Luiz de Queiroz", em Piracicaba/SP.

Table 5 - Grouped or isolated tipuanas and sibipirunas, gross precipitation (PT), throughfall (PI) and stem flow (Et), during the period of January to February 2007, at the campus of the College of Agriculture "Luiz de Queiroz", in Piracicaba, Brazil.

\begin{tabular}{|c|c|c|c|c|c|}
\hline Espécies & $\mathrm{PT}$ & Espécies & PI & Espécies & Et \\
\hline S234 & $5,69 \mathrm{a}$ & S234 & $4,67 \mathrm{a}$ & $\mathrm{S} 1$ & $0,82 \mathrm{a}$ \\
\hline $\mathrm{T} 234$ & $5,50 \mathrm{a}$ & $\mathrm{T} 1$ & $4,19 \mathrm{ab}$ & S5 & $0,24 \mathrm{a} b$ \\
\hline $\mathrm{T} 1$ & $5,33 \mathrm{ab}$ & S6 & $4,26 \mathrm{abc}$ & $\mathrm{T} 1$ & $0,08 \quad b$ \\
\hline S1 & $5,48 \mathrm{abc}$ & S5 & $3,91 \quad \mathrm{bc} \mathrm{d}$ & $\mathrm{T} 6$ & $0,07 \quad b$ \\
\hline $\mathrm{T} 5$ & $5,30 \mathrm{abc}$ & $\mathrm{T} 6$ & $3,90 \quad \mathrm{bc} \mathrm{d}$ & $\mathrm{T} 234$ & $0,01 \quad \mathrm{bc}$ \\
\hline S5 & $5,14 \quad \mathrm{bc}$ & T5 & $3,93 \quad \mathrm{c} \mathrm{d}$ & T5 & $0,05 \quad \mathrm{bc}$ \\
\hline T6 & $5,35 \quad \mathrm{bc}$ & $\mathrm{T} 234$ & 3,94 & S234 & 0,02 \\
\hline S6 & 5,40 & $\mathrm{~S} 1$ & 3,76 & S6 & 0,14 \\
\hline
\end{tabular}

Médias seguidas de mesma letra não diferem significativamente pelo teste Tukey a $5 \%$ de probabilidade.

\section{CONCLUSÕES}

A arquitetura da copa, a quantidade de área foliar e de galhos influenciaram, diretamente, na interceptação da água da chuva.

A Caesalpinia pluviosa apresentou maior média de interceptação na extremidade da copa $(60,6 \%)$ e a Tipuana tipu, no centro $(59,40)$, porém, ambas tiveram alta variabilidade em relação à porcentagem média de interceptação da chuva, tanto na extremidade como no centro da copa.

As espécies Caesalpinia pluviosa e Tipuana tipu apresentaram significativo potencial para serem plantadas no ambiente urbano, pois podem interceptar a água da chuva, principalmente a tipuana que mostrou mais predisposta a essa ação.

\section{REFERÊNCIAS BIBLIOGRÁFICAS}

CRUCIANI, D. E.; MACHADO, R. E.; SENTELHAS, P. C. Modelos da distribuição temporal de chuvas intensas em Piracicaba, SP. Revista Brasileira de Engenharia Agrícola e Ambiental, Campina Grande, v. 6, n. 1, p. 76-82, jan. 2002.

Cerne, Lavras, v. 16, n. 4, p. 547-555, out./dez. 2010
ENDRESS, P. K. Diversity and evolutionary biology of tropical flowers. Cambridge: Great Britain, 1994. 511 p.

FERREIRA, S. J. F.; LUIZÃO, F. J.; DALLAROSA, R. L.G. Precipitação interna e interceptação da chuva em floresta de terra firme submetida à extração seletiva de madeira na Amazônia Central. Acta Amazonica, Manaus, v. 35, n. 1, p. 55-62, nov. 2005.

GEIGER, R. O clima da camada do ar junto ao solo. 4. ed. Lisboa: Fundação Calouste Gulbenkian, 1961. 556 p.

HALLÉ, F.; OLDMAN, R. A. A.; TONLINSOM, P. B. Tropical trees and forest: an architectural analysis. Berlin: Springer Verlag, 1978. $200 \mathrm{p}$.

HOLWERDA, F.; SCATENA, F. N.; BRUIJNZEEL, L. A. Throughfall in a Puerto Rican lower montane rain forest: a comparison of sampling strategies. Journal of Hidrology, Illinois, v. 327, p. 592-602, Dec. 2006.

LEVIA JUNIOR, D. F.; FROST, E. E. A review and evaluation of stemflow literature in the hydrologic and biogeochemical cycles of forested and agricultural ecosystems. Journal of Hidrology, Illinois, v. 274, p. 1-29, Nov. 2003. 
LI, K. Y.; COE, M. T.; RAMANKUTTY, N.; JONG, R. Modeling the hidrological impacto $f$ land-use change in West África. Journal of Hydrology, Illinois, v. 337, p. 258-268, Jan. 2007.

LIKENS, G. E.; EATON, J. S. A polyurethane stemflow collector for trees and shrubs. Ecology, New York, v. 51, n. 5, p. 938-939, Sept. 1970.

LIMA, A. M. L. P.; COUTO, H. T. Z.; ROXO, J. L. C. Análise das espécies mais frequientes da arborização viária, na zona urbana central do município de Piracicaba/SP. In: CONGRESSO BRASILEIRO DE ARBORIZAÇÃO URBANA, 2.; ENCONTRO NACIONAL SOBRE ARBORIZAÇÃO URBANA, 5., 1994, São Luís. Anais... São Luís: Prefeitura municipal de São Luís, 1994. p. 555-578.

LIMA, W. P. Interceptação da chuva em povoamentos de eucalipto e de pinheiro. Revista IPEF, Piracicaba, n. 13, p. 75-90, 1976.

LIMA, W. P. Interceptação da chuva pela floresta. São Paulo: USP, 1986. 123 p.

LLOYD, C. R.; MARQUES, A. D. Spatial variability of throughfall and stemflow measurements in Amazonian rainforest. Agriculture Forest Meteorology, n. 42, p. 6373. Jan. 1988.

LORENZI, H. Árvores brasileiras: manual de identificação e cultivo de plantas arbóreas nativas do Brasil. Nova Odessa: Plantarum, 1992. 148 p.

MARTINS, M. A. G.; OLIVEIRA, D. M. T. Morfo-anatomia e ontogênese do fruto e da semente de Tipuana tipu (Benth.) O. Kuntze (Fabaceae: Faboideae). Revista Brasileira de Botânica, São Paulo, v. 24, n. 1, p. 109-121, mar. 2001.
McPHERSON, E. G. Structure and sustainability of Sacramento's urban forest. Journal of Arboriculture, Davis, v. 24, n. 4, p. 174-190, July 1998.

NÁVAR, J. The causes of stemflow variation in three semiarid growing species of Northeastern México. Journal of Hidrology, Illinois, v. 145, p. 175-190, Oct. 1993.

OLIVEIRA JÚNIOR, J. C.; DIAS, H. C. T. Precipitação efetiva em fragmento secundário da Mata Atlântica. Revista Árvore, Viçosa, v. 29, n. 1, p. 9-15, nov. 2005.

REGAlADO, C. M.; RITTER, A. Comment on "Fog precipitation and rainfall interception in the natural forests of Madeira Island (Portugal)". Agriculture Forest Meteorology, n. 150 , p. $133-134$, Sept. 2010.

VIDAL, W. N.; VIDAL, M. R. R. Botânica organografia. 3. ed. Viçosa, MG: UFV, 1992. 114 p.

XIAO, Q.; McPHERSON, E. G. Rainfall interception by Santa Monica's municipal urban forest. Urban Ecosystems, Davis, v. 6, p. 291-302, Sept. 2003.

XIAO, Q.; McPHERSON, E. G.; SIMPSON, J. R.; USTIN, S. L. Rainfall interception by Sacramento's urban forest. Journal of Arboriculture, Davis, v. 24, n. 4, p. 235-244, July 1998.

XIAO, Q.; McPHERSON, E. G.; USTIN, S. L.; GRISMER, M. E.; SIMPSON, J. R. Winter rainfall interception by two mature open-grow trees in Davis, California. Hydrological Processes, Davis, v. 14, p. 763-784, June 2000. 
